\title{
INOVAÇÃO EM TEMPOS DE CRISE: CAPACITAÇÃO A DISTÂNCIA
}

Raquel Rodrigues Bernardes - raquel.rodrigues@engenharia.ufjf.br

Universidade Federal de Juiz de Fora - Faculdade de Engenharia

Rua Doutor Norberto Gerhein, $n^{\circ}$ 165, Cerâmica

36080-400 - Juiz de Fora - Minas Gerais

Eduardo Fonseca Ribeiro-eduardo.fonseca@engenharia.ufjf.br Universidade Federal de Juiz de Fora - Faculdade de Engenharia Rua Tenente Barroso, $n^{o}$ 83, apto 102, Manoel Honório 36045-170 - Juiz de Fora - Minas Gerais

Júlia Couto Filgueiras-julia.couto@engenharia.ufjf.br

Universidade Federal de Juiz de Fora - Faculdade de Engenharia Rua Chanceler Oswaldo Aranha, $n^{\circ} 122$, apto 306, São Mateus 36025-007 - Juiz de Fora - Minas Gerais

Luiz Tadeu Dias Júnior-luiz.tadeu@engenharia.ufjf.br Universidade Federal de Juiz de Fora - Faculdade de Engenharia Rua Espírito Santo, $n^{\circ} 1290$, apto 301, Centro 36016-200 - Juiz de Fora - Minas Gerais

Yuri Mariano Carvalho - yuri.mariano@engenharia.ufjf.br Universidade Federal de Juiz de Fora - Faculdade de Engenharia Av. Presidente Costa e Silva, $n^{\circ}$ 2691, apt. 402, blc. C, São Pedro 36037-000 - Juiz de Fora - Minas Gerais

Júlia Righide Almeida-julia.righi@engenharia.ufjf.br Universidade Federal de Juiz de Fora-Departamento de Transportes e Geotecnia Rua Monsenhor Gustavo Freire, $n^{\circ} 21$, apto 205, São Mateus 36016-470 - Juiz de Fora - Minas Gerais

Resumo: Diversos setores econômicos e sociais interromperam suas atividades devido à pandemia da COVID-19 e modificaram as formas como se relacionavam, seja no mercado seja socialmente. Nesse contexto, este artigo visa ilustrar o evento on-line Maratona da Capacitação promovido pelo PET Engenharia Civil da UFJF e discutir seu impacto em participantes e organizadores. A atividade contou com mais de 1100 pessoas inscritas número superior, inclusive, ao de inscrições em eventos semelhantes realizados pelo grupo de forma presencial -, reforçando o compromisso do PET Engenharia Civil da UFJF em gerar, aprimorar e disseminar competências, indicando total alinhamento com as diretrizes do Programa de Educação Tutorial.

Palavras-chave: Treinamento. Minicurso. Workshop. Ensino. Extensão. 


\section{INTRODUÇÃO}

O novo coronavírus ocupa lugar chave nos noticiários e nas mídias sociais devido ao impacto que a pandemia vem causando nos diferentes territórios e segmentos sociais. A rapidez de contágio obrigou a sociedade a desenvolver novas formas de se comunicar e de relacionar interpessoalmente a fim de respeitar o isolamento social (SILVA et al., 2020).

Diversos setores reduziram ou interromperam suas atividades para evitar o contágio pelo vírus. No caso das universidades federais brasileiras, todas chegaram a suspender as aulas presenciais em algum momento no mês de março, não havendo consenso quanto à melhor maneira para se lidar com a pandemia (AULAS..., 2020). A Universidade Federal de Juiz de Fora (UFJF), por exemplo, optou por suspender as aulas presenciais; no entanto, segmentos universitários como as empresas juniores e os Programas de Educação Tutorial (PET) continuam ativos, reaprendendo a se organizar frente o desafio do trabalho remoto.

Nesse contexto, o PET da Engenharia Civil da UFJF se viu obrigado a renovar seu planejamento anual, adaptando projetos existentes e criando novas atividades passíveis de serem trabalhadas remotamente. A fim de reafirmar seu papel enquanto modificador da realidade acadêmica e formador de indivíduos conscientes de seu papel na sociedade (CARVALHO et al., 2019), o PET Engenharia Civil da UFJF promoveu de forma pioneira um evento on-line chamado Maratona da Capacitação com capacitações gratuitas abertas a qualquer interessado que quisesse se profissionalizar durante a quarentena.

Logo, este artigo visa apresentar como a atividade foi concebida e os resultados obtidos com o evento on-line, que reafirmam o compromisso do PET Engenharia Civil da UFJF em gerar, aprimorar e disseminar competências.

\section{METODOLOGIA}

A Maratona da Capacitação foi pensada, inicialmente, para capacitar e motivar os membros do PET Engenharia Civil da UFJF durante a quarentena e para aprimorar a qualidade das atividades pós-pandemia. Petianos e petianas responderam a um formulário interno (elaborado com a ferramenta Google ${ }^{\circledR}$ Forms) para listar as competências que cada qual almejava desenvolver ou se predispunha a oferecer ao grupo mediante treinamento. Dessa forma, foram elencados ministrantes para cada capacitação, incluindo membros do PET (ativos e egressos) e indivíduos externos.

A fim de impactar mais pessoas com as capacitações levantadas, optou-se por abrir parte delas ao público (Quadro 1).

Quadro 1 - Capacitações organizadas pelo PET Engenharia Civil da UFJF

\begin{tabular}{|c|c|c|}
\hline Capacitações internas & \multicolumn{2}{|c|}{ Capacitações Externas } \\
\hline Scrum & MS Project ${ }^{\circledR} I$ & Gestão de Projetos \\
\hline Google ${ }^{\circledR}$ Forms & MS Project ${ }^{\circledR}$ II & Revisão de Literatura \\
\hline $\begin{array}{l}\text { Otimização de Marketing } \\
\text { (SEO) }\end{array}$ & $\begin{array}{c}\text { Estruturação de Artigos } \\
\text { Científicos }\end{array}$ & PNL aplicado a Liderança \\
\hline $\begin{array}{c}\text { Visual Basic for } \\
\text { Applications (VBA) }\end{array}$ & Compostagem & Camtasia ${ }^{\circledR}$ Studio \\
\hline Slide ${ }^{\circledR}$ (software) & Técnicas de Marketing & OBS Studio $^{\circledR}$ \\
\hline Gerenciamento de Equipes & Finanças & Photoshop ${ }^{\circledR}$ Básico \\
\hline
\end{tabular}

Fonte: Arquivo interno. 
Logo, foram ofertados 12 (doze) treinamentos abertos à comunidade durante os meses de abril e maio de 2020, cada qual com duas horas de duração. Cada ministrante produziu material de apoio a ser utilizado durante a capacitação ou disponibilizado posteriormente, a fim de complementar o estudo no assunto.

As plataformas on-line utilizadas para as capacitações foram o $\mathrm{Jitsi}^{\circledR}$ — para maior interação visual e comunicativa entre participantes e ministrante - e o canal do PET Engenharia Civil da UFJF no YouTube ${ }^{\circledR}$ - para aumentar a visibilidade dessa rede social do grupo e disponibilizar os conteúdos gravados na web.

Para comprovar a presença dos inscritos nos treinamentos, foram emitidos certificados para os participantes mediante formulário a ser preenchido nos momentos finais de cada capacitação. Solicitou-se, também, feedbacks aos participantes, a fim de aprimorar a atividade.

O contato com o público externo foi estabelecido através das redes sociais do grupo. Contou-se, também, com o apoio da própria UFJF, que noticiou a atividade em suas redes (PET..., 2020).

A inscrição nos treinamentos se deu através de formulários on-line disponibilizados semanalmente no Instagram ${ }^{\circledR}$ e no site oficial do PET Engenharia Civil da UFJF (que já listava todas as capacitações a serem ofertadas e seus respectivos formulários de inscrição). Os dados coletados com os formulários foram: nome do(a) interessado(a), celular e profissão/curso. Os inscritos receberam via e-mail e Whatsapp ${ }^{\circledR}$ os links de acesso às plataformas para as capacitações.

Dessa forma foi possível acompanhar o número de inscritos, as regiões do país a qual pertencem e a adesão na atividade, bem como o impacto da atividade na formação de petianas e petianos.

\section{RESULTADOS E DISCUSSÃO}

\subsection{Alcance da atividade}

As capacitações abertas ao público contaram com 1878 inscrições (Figura 1).

Figura 1 - Total de inscrições por treinamento. As capacitações estão ordenadas segundo a oferta, sendo a de MS Project $^{\circledR}$ I a primeira e a de Photoshop ${ }^{\circledR}$ Básico a última.

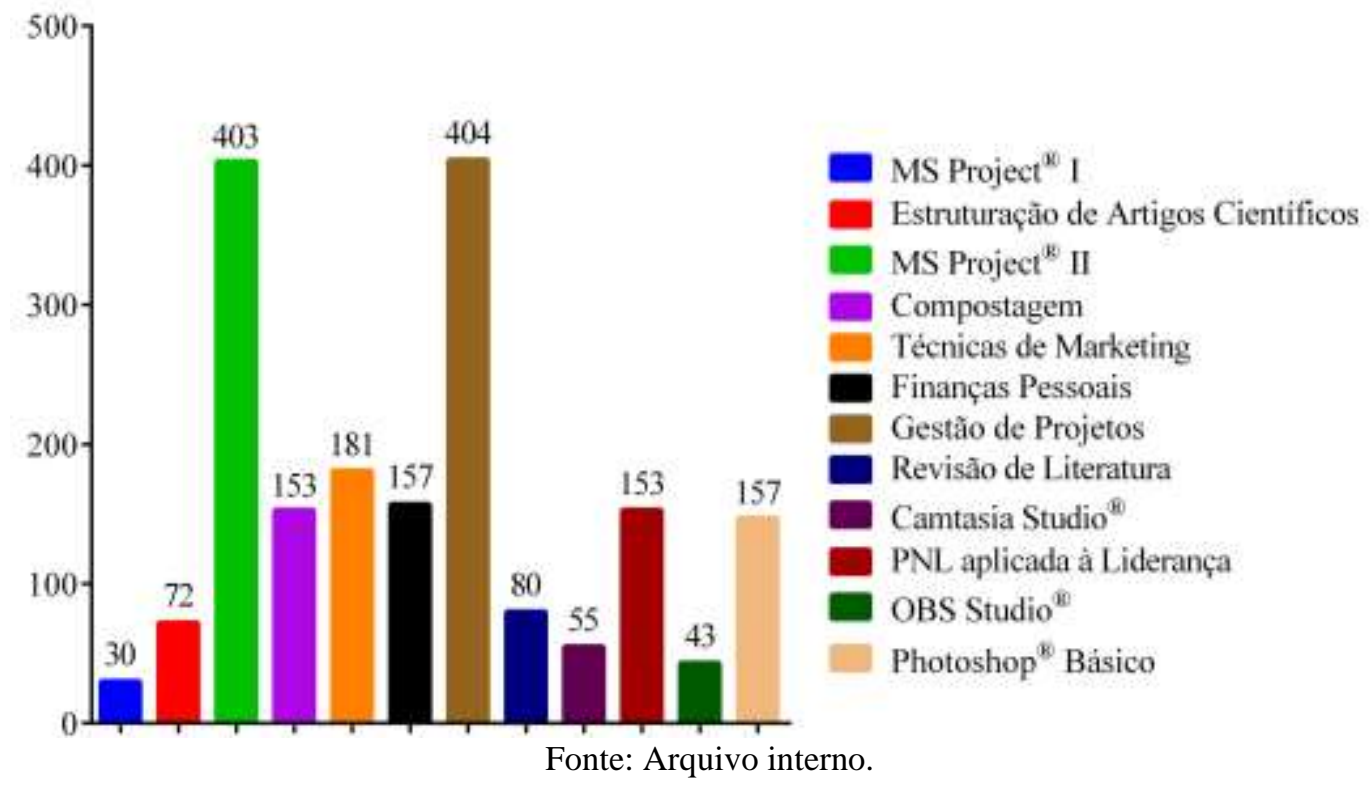


O aumento no número de inscritos a partir da segunda parte da capacitação em MS Project $^{\circledR}$ pode estar associado à divulgação do evento realizada pela UFJF em suas redes sociais (PET..., 2020). Ao fim, 1114 pessoas de todo o país (de 25 estados mais o Distrito Federal) e inclusive do exterior (duas pessoas da Itália e outra da Suíça) se inscreveram nas capacitações ofertadas pelo PET Engenharia Civil da UFJF (Figura 2).

Figura 2 - Total de pessoas inscritas agrupadas por região de origem.

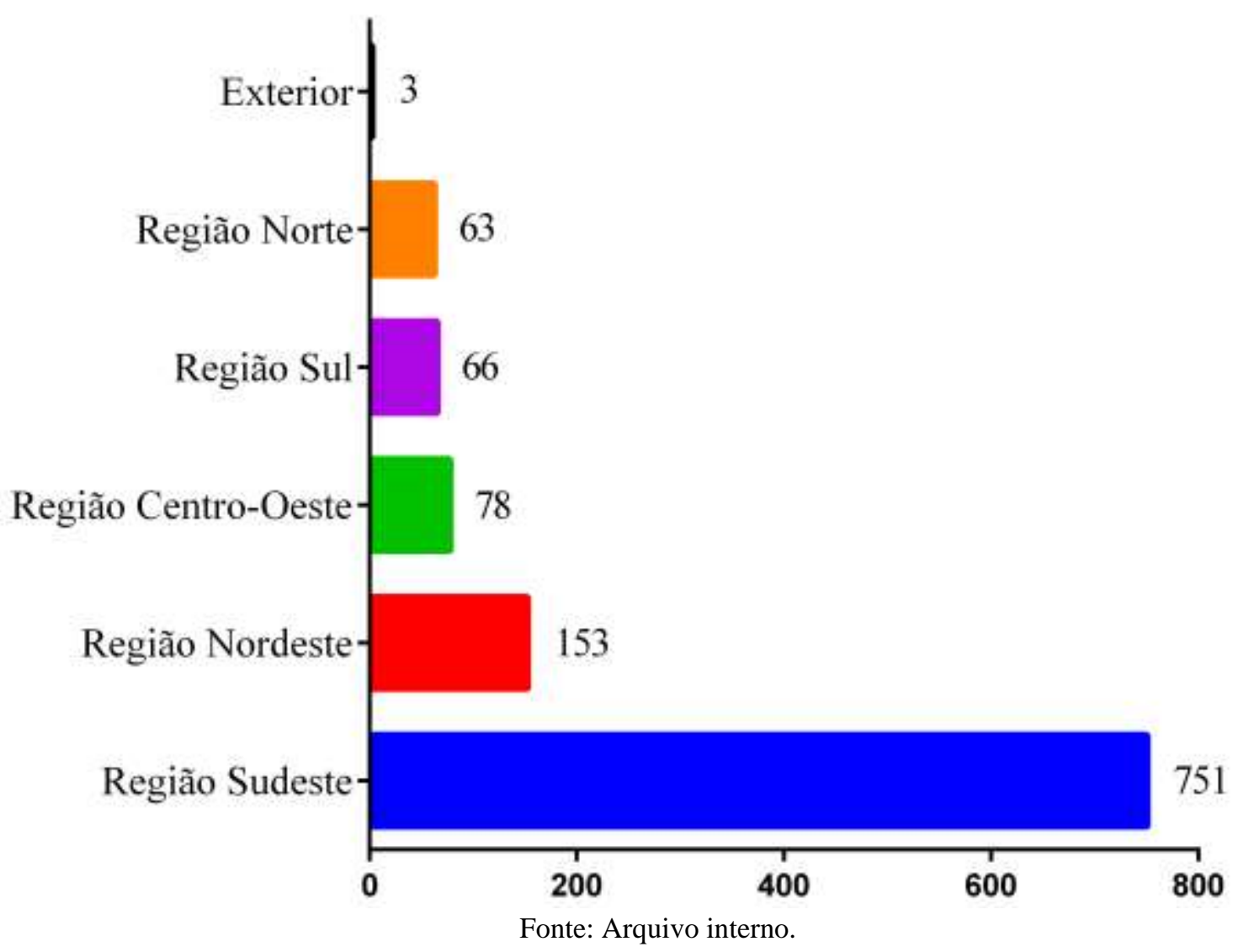

A razão entre o número de pessoas inscritas nos treinamentos pelo total de inscrições é de 0.59 , indicando que houveram inscritos na atividade que se interessaram por mais de um treinamento - o que serve de incentivo para que o PET Engenharia Civil da UFJF continue promovendo atividades semelhantes, tanto para o corpo discente da universidade quanto para a comunidade externa.

\subsection{Evasão}

Comparando-se o número de certificados gerados com o número de inscrições para cada treinamento (Tabela 1), poder-se-ia inferir uma alta taxa de evasão por parte dos inscritos (de 70,18\%). A partir de dados atualizados da Associação Brasileira de Ensino a Distância (ABED, 2018), calcula-se que o valor médio de evasão nos cursos livres ofertados por instituições de ensino nacionais seja de cerca de 25,46\% (considerando-se somente os cursos livres que fazem esse tipo de acompanhamento; isto é, 72,8\% dos cursos). No pior dos cenários, a evasão nos treinamentos ofertados seria quase três vezes maior do que a média 
nacional. Como a certificação era uma etapa opcional das capacitações, a taxa de evasão calculada não é fidedigna.

Tabela 1 - Comparação entre o número de inscritos e o de certificados gerados.

\begin{tabular}{|c|c|c|c|}
\hline Curso & $\mathrm{n}^{\mathrm{o}}$ de inscritos & $\mathrm{n}^{\mathrm{o}}$ de certificados & $\%$ certificados \\
\hline Camtasia Studio $^{\circledR}$ & 55 & 37 & $67,27 \%$ \\
\hline Compostagem & 153 & 51 & $33,33 \%$ \\
\hline Estruturação de Artigos & 72 & 54 & $75,00 \%$ \\
\hline Finanças Pessoais & 157 & 51 & $32,48 \%$ \\
\hline Gestão de Projetos & 404 & 93 & $23,02 \%$ \\
\hline MS Project I ${ }^{\circledR}$ & 30 & 19 & $63,33 \%$ \\
\hline MS Project II ${ }^{\circledR}$ & 403 & 44 & $10,92 \%$ \\
\hline OBS Studio $^{\circledR}$ & 43 & 21 & $48,84 \%$ \\
\hline Photoshop ${ }^{\circledR}$ Básico & 147 & 41 & $27,89 \%$ \\
\hline PNL aplicado à Liderança & 153 & 53 & $34,64 \%$ \\
\hline Revisão de Literatura & 80 & 39 & $48,75 \%$ \\
\hline Técnicas de Marketing & 181 & 57 & $31,49 \%$ \\
\hline Total & 1878 & 560 & $29,82 \%$ \\
\hline
\end{tabular}

A evasão nas capacitações poderia ser explicada pelo fato de os formulários para inscrição terem sido todos disponibilizados no site do grupo desde o início da atividade, o que pode ter incentivado que muitas pessoas se inscrevessem e, com o passar do tempo, perdessem o interesse nos treinamentos.

\subsection{O impacto do Programa de Educação Tutorial}

O isolamento social durante a quarentena aumentou a busca por capacitações via web (CRESCE..., 2020). Mesmo havendo críticas quanto ao caráter extensionista de minicursos abertos à comunidade (MOREIRA, 2014), a Maratona da Capacitação reafirma o compromisso do PET Engenharia Civil da UFJF com a extensão ao atingir número tão grande de pessoas (222 pessoas requereram certificados) de forma virtual, capacitando a população de forma dinâmica e gratuita. $\mathrm{O}$ evento virtual superou, inclusive, atividades presenciais semelhantes realizadas anteriormente, como a Semana da Evolução (CARVALHO et al., 2020). Além disso, a atividade em questão auxilia na redução da evasão aos períodos iniciais, visto que os participantes possuem contato com as diversas tecnologias e softwares utilizados de maneira profssional.

Os treinamentos on-line contribuíram, também, para desenvolver, dentre outras competências, a didática, a oratória e a resiliência de petianas e petianos. Logo, mesmo em um contexto pandêmico, o PET Engenharia Civil da UFJF mantém-se alinhado às diretrizes do Programa de Educação Tutorial em melhorar a formação discente (MINISTÉRIO DA EDUCAÇÃO, 2006).

Por fim, o alcance obtido nas redes sociais permitirá que o PET Engenharia Civil da UFJF contacte pessoas de todo o país, visto que os dados coletados permitem que seja construído um canal de comunicação com centenas de pessoas de todas as regiões e que provavelmente pouco sabem sobre a importância da Educação Tutorial e o papel dos grupos PET em si. O vínculo pelas plataformas digitais facilitará o contato para divulgar possíveis 
edições futuras da Maratona da Capacitação e outras atividades voltadas para a comunidade, disseminando a Educação Tutorial e a Engenharia Civil.

\section{CONCLUSÃO}

O artigo ilustra a concepção e os resultados obtidos pelo PET Engenharia Civil da UFJF com a Maratona da Capacitação, evento on-line aberto à comunidade que visa capacitar profissionalmente qualquer interessado de forma gratuita e dinâmica. A Maratona ocorreu durante os meses de abril e maio de 2020 e contou com 12 (doze) capacitações abertas ao público. No total, mais de 1100 pessoas de todo o país e do exterior se inscreveram na atividade, contribuindo para que o PET Engenharia Civil da UFJF crie uma ampla rede de contatos para divulgar suas atividades e disseminar a Educação Tutorial e a Engenharia Civil.

O evento via web contou com maior participação do que eventos presenciais semelhantes realizados anteriormente. Logo, por mais que o evento só atinja a parcela da população que possui acesso à Internet, levanta-se a possibilidade de realizar atividades de Extensão de forma remota durante a pandemia do COVID-19.

Além disso, as capacitações aprimoraram competências sociais e intrapessoais de petianas e petianos, o que reforça o compromisso do PET Engenharia Civil da UFJF com as diretrizes do Programa de Educação Tutorial de transformar a sociedade através da educação.

Espera-se que o evento inspire outros segmentos universitários e Instituições públicas de Ensino Superior a desenvolver atividades semelhantes para capacitar a população de forma remota a fim de retribuir, mesmo que parcialmente, o investimento feito nas Universidades Públicas para formar profissionais competentes.

\section{REFERÊNCIAS}

ABED - Associação Brasileira de Educação a Distância. Censo EAD.BR: relatório analítico da aprendizagem a distância no Brasil 2018. Curitiba: InterSaberes, 2019.

AULAS estão suspensas em todas as 69 universidades do país. APUFSC Sindical. 20 abr. 2020. Disponível em: <https://www.apufsc.org.br/2020/03/20/aulas-estao-suspensas-em-todas -as-69-universidades-federais-do-pais/>. Acesso em 28 mai. 2020.

CARVALHO, Y. M. et al. O Programa de Educação Tutorial como agente transformador e modulador de competências de um engenheiro. In: XLVII Congresso Brasileiro de Educação em Engenharia e II Simpósio Internacional de Educação em Engenharia da ABENGE, 2019, Fortaleza - CE. Anais... Fortaleza: ABENGE, 10 p., 2019.

CARVALHO, Y. M. et al. Semana da Evolução como complemento ao desenvolvimento de competências na graduação. In: XXV Encontro Nacional dos Grupos PET, 2020, Curitiba PR. Anais... Curitiba: UEM/UFPR, 5 p., 2020. (in press)

CRESCE busca por cursos online durante a quarentena. Terra. 24 abr. 2020. Disponível em: <https://www.terra.com.br/noticias/dino/cresce-busca-por-cursos-online-durante-a-quarentena ,08d2494fad92dc8651192e4b7db284b1136zce9t.html>. Acesso em 28 mai. 2020. 
"Os desafios para formar hoje o engenheiro do amanhá"

MINISTÉRIO DA EDUCAÇÃO. Programa de Educação Tutorial - PET: Manual de

Orientações Básicas. Secretaria de Educação Superior, Departamento de Modernização e Programas da Educação Superior, Coordenação Geral de Relações Acadêmicas de Graduação. 2006. 25 p.

MOREIRA, J. da S. Extensão universitária: entre o assistencialismo e o compromisso com o povo. FRAGMENTOS DE CULTURA, Goiânia, v. 24, especial, p. 25-30, dez. 2014.

PET de Engenharia Civil oferece cursos de capacitação on-line. UFJF. Juiz de Fora, 27 abr. 2020. Notícias. Disponível em: <https://www2.ufjf.br/noticias/2020/04/27/pet-de-engenhariacivil-oferece-cursos-de-capacitacao-on-line/>. Acesso em 28 mai. 2020.

SILVA, J. B. da; MUNIZ, A. M. V. Pandemia do Coronavírus no Brasil: Impactos no Território Cearense. Espaço e Economia [online]. v. 17, 2020. DOI: 10.4000/espacoeconomia.10501.

\section{INOVATION IN A TIME OF CRISIS: DISTANCE CAPACITATION}

Abstract: Several economic and social sectors interrupted their activities and changed the ways they relate due to the COVID-19 pandemic. In this context, this paper aims to illustrate the online event Maratona da Capacitação promoted by the PET Engenharia Civil from UFJF, and discuss its impact on participants and organizers. The activity had more than 1100 people registered - even more than the number of registrations in similar events held by the group in person -, reinforcing the commitment of the PET Engenharia Civil from UFJF to generate, improve and disseminate competencies, indicating total alignment with the Tutorial Education Program guidelines.

Keywords: Training. Minicourse. Workshop. Teaching. Extension. 